\title{
O nobre seqüestrador ou o hibridismo segundo Antonio Torres
}

\author{
Ligia Vassalo \\ Universidade Federal do Rio de Janeiro
}

RESUMO: A PARTIR DO ROMANCE BRASILEIRO O NOBRE SEQÜESTRADOR, DE ANTONIO TORRES, REALIZA-SE UMA REFLEXÃO SOBRE O HIBRIDISMO NA LITERATURA BRASILEIRA CONTEMPORÂNEA.

ABSTRACT: BASED ON THE BRAZILIAN NOVEL O NOBRE SEQÜESTRADOR, BY ANTONIO TORRES, A REFLECTION ABOUT HYBRIDISM ON CONTEMPORARY BRAZILIAN LITERATURE IS CARRIED OUT. 
nobre seqüestrador ${ }^{1}$, romance do escritor baiano Antonio Torres publicado em 2003, dá ensejo a refletir sobre a tendência ao hibridismo na literatura brasileira atual.

Romance e hibridismo são duas categorias que se remetem mutuamente, uma vez que, ao longo de sua construção, o gênero romanesco se tornou um composto híbrido por excelência, já que incorporou à sua estrutura outros gêneros, como o ensaio, a carta, a biografia, as fontes de cultura oral e assim por diante. Isto ocorre, como sabemos, desde os primeiros balbucios até sua maturidade literária, com a Comédia Humana, de Balzac, no século XIX, momento em que atinge sua forma canônica.

A partir do século XX, entretanto, tem sido muito operoso o trabalho de desconstrução desta mesma forma canônica, fato que se pode constatar não só nas obras das diversas vanguardas como também nas grandes experimentações do período, situação por demais conhecida. Esta desconstrução, em alguns casos, tem a ver com o hibridismo, como se verifica em parte na literatura da América Latina.

De todo modo, o hibridismo, no tocante à forma romanesca, é apenas uma das faces da questão, que envolve igualmente conceitos e elaborações teóricas. Tais discussões enriqueceram-se muito, em especial no último quartel do século XX, graças à contribuição de estudiosos provenientes de áreas geográficas periféricas da cultura ocidental, de que destacamos alguns, como o palestino Edward Said, o anglo-indiano Homi Bhabha, o peruano Antonio Cornejo Polar, o argentino Néstor Garcia Canclini, os quais, com suas teorias, põem em questão princípios e valores eurocêntricos que por tanto tempo foram impostos como hegemônicos, em particular na América Latina, continente que ocupa nossos interesses e análises.

Essas teorias exóticas, que por tanto tempo nos sufocaram, apagam a especificidade de nosso continente, de si mesmo já híbrido devido à conjunção de autóctones, europeus e africanos, continente que é o "espaço-entre" tão bem conceituado por Silviano Santiago (1978), no qual as idéias estão fora do lugar, para evocar a célebre expressão de Roberto Schwarz (1977).

1 TORRES, Antonio. O nobre seqüestrador. Rio de Janeiro, Record, 2003. 
A esse respeito, tem razão Eduardo Coutinho (2003, p. 133) ao invocar Edward Said (1983), para quem a circulação de idéias, apesar de ser uma condição básica da atividade intelectual, não pode desvincular estas mesmas idéias de sua historicidade e de seu contexto originários, com os quais mantêm fortes laços, e que as interferências na apreensão das teorias do primeiro mundo, caso sejam transpostas sem perspectiva crítica para um novo contexto, podem levar a interpretações duvidosas e inadequadas.

Valoriza-se agora, com Homi Bhabha, a emergência dos interstícios, dos entre-lugares, a sobreposição e o deslocamento dos domínios da diferença, geradores de hibridismos culturais que emergem em momentos de transformação histórica. Daí a necessidade de erigir-se um novo paradigma e é nesse sentido que a fronteira se torna o lugar a partir do qual algo começa a se fazer presente, em um movimento ambivalente (Bhabha, 1998, p. 24).

Lembramos que fronteiras, sincretismo, mestiçagem e hibridismo constituem vieses de um só fenômeno, ligado às questões interculturais. Aliás, este último termo, que envolve um movimento de interação, troca, intercessão entre dois pólos, é preferível ao de multiculturalidade, uma vez que esta última categoria, ao contrário, leva ao separatismo, ao isolamento e, sobretudo, ao gueto.

A hibridação é um termo detonante, que aponta para uma questão crucial. Para um dos mais importantes teóricos do tema, Néstor Garcia Canclini, "a hibridação não é sinônimo de fusão sem contradições, mas, sim, que pode ajudar a dar conta de formas particulares de conflito, geradas na interculturalidade recente em meio à decadência de projetos nacionais de modernização da América Latina" (Canclini, 2004, p. XVIII).

$\mathrm{Ou}$, dito de outro modo, Canclini entende por hibridação aqueles "processos culturais nos quais estruturas ou práticas discretas, que existem de forma separada, se combinam para gerar novas estruturas, objetos, práticas" (2004, p. XIX). Eles contribuem assim para identificar e explicar múltiplas alianças fecundas, como a junção entre a estética popular e a dos turistas, a das culturas étnicas nacionais com as das metrópoles, etc.

Corrobora nessa direção a afirmação de Mario Valdéz, para quem os "sistemas subalternos reformulam, ressemantizam e criam estruturas híbridas e imagens sincréticas, que em conjunto é o que lhes tem dado seu caráter distintivo e que talvez, para entender o sincrético, tivéssemos que pensar dialeticamente" (2000, p. 9). 
É assim que têm funcionado a cultura e a literatura na América Latina incluindo-se aí o Brasil -, segundo o parecer coincidente de estudiosos recentes. A propósito, Antonio Cornejo Polar (2000, p. 22) observa que nos últimos anos é freqüente detectar, sobretudo no romance regional, certos elementos não romanescos que costumam ser descritos como próprios do mito, da epopéia, da História, do testemunho, da denúncia social, dos relatos folclóricos, etc. A partir de certo conceito de romance, essas formas heterogêneas são percebidas como impurezas, sem que se suspeite que tal heterogeneidade produz um desvio peculiar na constituição do gênero, além de representar um conflito entre duas culturas distintas: a índole de um universo agrário, semifeudal, e recursos e perspectivas marcados pela procedência citadina e burguesa. Este é um fato especificamente literário, que consiste na modificação da estrutura de gênero, inclusive em seus aspectos formais. Por isso, na América Latina, é difícil ater-se aos habituais julgamentos e requisitos sobre as virtualidades do romance, especialmente se estas virtudes são concebidas em termos de um contexto diverso, como o europeu ou o norte-americano.

Desse modo, ao que tudo indica, Cornejo Polar advoga que a estrutura formal híbrida, no romance, é uma especificidade latino-americana. Característica semelhante é também apontada por Ana Cecília Olmos, em artigo na revista Bravo! (Olmos, 2004, 92-96) a propósito da literatura argentina do pós-boom, que mistura gêneros diferentes para pensar um país diferente. Essa produção recente tem no hibridismo, na mistura de gêneros, a sua mais singular característica, pois ela

optou por entremear a ficção com outros registros discursivos (a História, o jornalismo, o testemunho, a crítica literária, a autobiografia), explorando uma zona de indefinição genérica para seus relatos. A hibridez, apesar da idéia de esterilidade que a palavra encerra, seria, então, o traço que define uma singularidade literária que rendeu e continua a render uma volumosa narrativa.

A contaminação textual está na base de romances que, ligados às cenas políticas do país, interrogam uma experiência histórica que reitera, sob diferentes desígnios (ditaduras militares e projetos neoliberais), a brutal instauração e o fortalecimento de sistemas de controle e exclusão social (Olmos, 2004, p. 93). 
Informa ainda o mesmo texto crítico que, com maior sutileza estética e em estreito diálogo com o discurso histórico, outras ficções voltam-se em direção ao passado na tentativa de compreender os conflitos do presente (Olmos, 2004, p. 94).

As ponderações de Ana Cecília Olmos se aplicam perfeitamente ao romance O nobre seqüestrador (2003), que nos propomos a analisar. Buscamos com isso detectar de que modo seu autor procede para compor um texto que escapa às categorias já codificadas, misturando e recombinando procedimentos conhecidos porém provenientes de áreas distintas, nem sempre estritamente literárias, de modo a atingir um resultado ímpar e novo, fora das classificações habituais. É indispensável ter em mente, contudo, que esta tendência, embora presente na literatura brasileira atual, está longe de ser majoritária, porque de maneira geral a literatura brasileira ainda é bastante pautada pela escrita linear e pela fatura realista-naturalista, situação que não cabe aqui desenvolver.

Estas duas tendências, por sinal, são bem visíveis no conjunto da obra de Antonio Torres, na qual dois títulos, Meu querido canibal (2000) e O nobre seqüestrador (2003), evidenciam uma nítida virada de rumo. Neles, em especial no último, como veremos a seguir, entremeiam-se gêneros como o romance histórico e o de aventuras, a biografia e as memórias, poemas e letras de música, cartas e documentos históricos, ensaio e até mesmo matéria de jornal.

Observa-se logo de saída que, devido a esta imbricação de gêneros, nenhuma das subcategorias de romance manifesta-se textualmente em sua ortodoxia. Assim, embora não configurem romances históricos canônicos, ambos os títulos têm claros envolvimentos com situações e personagens históricos que, além do mais, ancoram-se no Rio de Janeiro, mais particularmente em dois momentos assinalados pela presença de franceses no Brasil, nos séculos XVI e XVIII respectivamente. Tal circunstância já de si é híbrida, uma vez que os eventos que lhe servem de eixo pertencem à História desses dois países. O primeiro livro focaliza Cunhambebe, o líder da Confederação dos Tamoios, no século XVI, árduo combatente dos portugueses porém grande aliado de François Durand de Villegagnon, o idealizador da França Antártica. O segundo título se dedica a René Duguay-Trouin, corsário francês do tempo de Luís XIV, que seqüestrou a cidade do Rio de Janeiro por mais de 50 dias em 1711. Por sinal, o diário de bordo deste último, publicado originalmente em 1740, mereceu uma recente edição no Brasil (Duguay-Trouin, 2000). 
Por outro lado, apesar de tais romances serem centrados nos feitos e traços de importantes personalidades, em nenhum dos casos pode-se falar de romances estritamente biográficos, porque em ambos Antonio Torres precisou se valer de suas astúcias de escritor para preencher as lacunas e os silêncios que a História não registrou. Quanto a Cunhambebe, além do mais, Torres teve que dar vida a um personagem vindo de uma outra cultura completamente diversa, até mesmo por pertencer a uma sociedade ágrafa. Já René Duguay-Trouin, por seu turno, é desmistificado e humanizado, mostrado com as fragilidades e insucessos de um herói-canalha.

O romance de aventuras pautado no corsário divide-se equilibradamente em três partes e tem dois personagens principais, uma voz masculina e uma feminina, respectivamente agente e paciente da mesma história, que se expressam em primeira pessoa do singular ao longo do texto. Este se concentra sobre o primeiro, referido no título, representado pela jactanciosa estátua de René Duguay-Trouin, o agressor que se gaba de seus feitos aventurosos e guerreiros. Contrapondo-se a ele situa-se, em plano menor, o objeto - ou melhor, o espaço - de sua façanha maior, a cidade do Rio de Janeiro, denominada a Praça do Rei, a qual se lastima de sua posição de mulher vilipendiada e vítima dos maus tratos recebidos naquele momento, em 1711, e aliás hoje também, lamentando-se como um coro de tragédia grega.

É indispensável salientar que a personificação da estátua do corsário, bem como a da Praça do Rei, constitui uma grande invenção de Antonio Torres. Aliás, o escritor dá o mesmo tratamento a outras cidades mencionadas na narrativa, como La Rochelle e Niterói. Ressaltemos que este recurso retórico, pelo qual a Aurora, em Homero, tem dedos cor-de-rosa, é raramente ou quase nunca empregado em um romance moderno, embora seja muito comum não só na epopéia como na poesia neoclássica setecentista, conferindo desse modo coincidência temporal entre o procedimento literário e a época do personagem biografado.

Por outro lado, como os seres que foram personificados não são animados, eles podem ultrapassar as contingências humanas e logram, assim, fugir às injunções temporais do romance, o que os capacita a abordar o presente e o futuro em relação a eles, em igualdade de condições. Aliás, esta condição da presbiopia, ou vista de longe, ocorre também freqüentemente na Divina Comédia, de Dante - uma obra fulcral mas igualmente inclassificável e híbrida. 
Por esses motivos a linearidade temporal da narrativa de Torres é freqüentemente interrompida; ela se concentra no século XVIII, mais particularmente em episódios de 1711, sendo porém entrecortada por remissões ao presente da enunciação e a alusões explícitas aos dias de hoje.

Em O nobre seqüestrador aparece ainda uma terceira voz narrativa, anônima, a de um narrador onisciente que se desdobra ou se confunde com um narratário que é, ao mesmo tempo, não só o ouvinte silente das peripécias da estátua falante - o "você" a quem ela se dirige sem obter resposta, como em O grande sertão: veredas, de Guimarães Rosa - como também é o "brasileiro" do texto, que vai à França à procura de informações históricas para seu livro. Ou seja, o ouvinte mudo revela-se, portanto, como sendo o autor do romance, com alguns problemas profissionais e existenciais a resolver. Mas nem por isso tal artimanha dá ao texto um caráter confessional de obra memorialística, porque ilumina apenas uma fração dessas confissões.

À figura do autor do romance, contudo, não bastam as digressões, pois ele se intromete na história de seu biografado e começa a falar de si, embora em terceira pessoa, inserindo na narrativa principal suas preocupações pessoais bem como seus passos em relação à pesquisa empreendida para a elaboração do livro. Este ardil narrativo não chega a ser equivalente ao que se lê nos roteiros de filmes, aproximando-se ao invés daquilo que alguns denominam o making of da obra, ou o desnudamento de sua preparação.

Não contente em desconstruir a estrutura das diversas modalidades do gênero romanesco aqui mencionadas, Antonio Torres vai ainda mais longe, porque mistura técnicas redacionais próprias da ficção com peculiaridades de textos que provêm de outros campos, como a crônica policial e o ensaio, entre outros.

$\mathrm{Na}$ fatura de $\mathrm{O}$ nobre seqüestrador é interessante explorar a presença de inúmeros textos não propriamente ficcionais, a saber: as múltiplas cartas de diferentes signatários, incorporadas ao texto entre aspas; a presença implícita ou explícita de diversos documentos históricos; as transcrições de diários de bordo, tanto da viagem transatlântica (p. 84; p. 189) quanto da campanha francesa (p.189-215); as listas diversas (p. 175; p. 177; p. 221); o currículo de Francisco Távora, o novo governador da cidade (p. 220); uma citação do livro do historiador francês Roger Vidal sobre a imagem de René Duguay-Trouin (p. 123) e certamente várias outras ocorrências. 
Dentre tantos fragmentos, alguns são mais destacados tipograficamente, como o que consideramos duas colagens de matéria de jornal, uma tomada a O Globo de 3 de dezembro de 2002 (p. 142-143) e outra ao Jornal do Brasil de 25 de fevereiro de 2003 (p. 247-248). Estas transposições operam uma espécie de mise en abyme, porque abordam, na atualidade, a questão do medo, comum a nossa época e ao século XVIII, que decorre da insegurança dos citadinos - não só pelo ataque do corsário, no passado, bem como pela recente ocupação da cidade do Rio de Janeiro por parte dos narcotraficantes, em 2003, ação interpretada textualmente como um seqüestro. Aliás, muito a propósito, a transcrição do Jornal do Brasil incrustrada no livro remete à empreitada de Duguay-Trouin.

Sem destaque tipográfico e embaralhadas em meio às conjeturas da estátua falante e da Praça do Rei, surgem passagens textuais informativas de cunho histórico e geográfico sobre as cidades associadas às atividades do corsário, como Saint-Malo, La Rochelle, Brest e Rio de Janeiro, que mais parecem saídas das páginas de um guia turístico ou de uma enciclopédia. Em compensação, tal assepsia é contraposta pelos excessos de subjetividade das figuras personificadas, em especial a linguagem vulgar usada pertinentemente pela estátua em certas situações, constituindo entretanto um verdadeiro anacronismo em relação à fala local no século XVIII.

Não se pode deixar de mencionar um outro aspecto muito interessante do último romance publicado por Antonio Torres, que concorre para ressaltar a originalidade de seu hibridismo formal. Trata-se da incorporação de elementos habitualmente tidos como paratextuais, tal como bibliografia, agradecimentos e créditos, os quais costumam constar de trabalhos acadêmicos e ensaios, mas nunca ou raramente de obras ficcionais. Só conheço esta ocorrência no belíssimo poema O oratório dos Inconfidentes, de Domício Proença Filho (1989), outra obra de fatura igualmente híbrida.

A estes aspectos acrescenta-se também um outro, proveniente da produção ensaística, como as passagens caracterizadas pela função metalingüística, encontradas sobretudo nas várias explicações sobre as especificidades e diferenças existentes entre corso e pirata (p. 16; p. 26; p. 28; p. 43). Quer-nos parecer que tais elementos, junto com os recortes-colagens de jornal, estão presentes para burlar o pacto com o leitor, desnudando a pesquisa empreendida pelo escritor e seu making of do romance. 
A esfera dos textos ortodoxamente literários também é visível, sob diferentes modalidades, nas inserções textuais de $O$ nobre seqüestrador. Destaquemos da saída as letras de música que pontuam o texto, estrategicamente situadas no princípio, no meio e no fim do romance, de modo a constituir uma espécie de marcação de suas três partes e três vozes. A primeira delas, colocada à guisa de epíteto à obra, é a “Canção de Duguay-Trouin”, de Chico Buarque e Edu Lobo, criada originalmente para a peça $O$ corsário do rei, de Augusto Boal. A segunda é uma anônima cantiga de ninar sobre o famoso corsário, que na França "os pescadores cantavam para as suas crianças" (p.113). Ambas se concentram sobre a figura do protagonista masculino, preponderante na primeira parte do romance, como sabemos, ao passo que a terceira letra de música, incluída ao final da terceira parte da obra, é a transcrição de um conhecido hino de louvor à cidade do Rio de Janeiro (p. 243), a voz feminina da Praça do Rei.

Arrolamos ainda diversas citações de obras literárias ao longo do romance: o inferno segundo Jean-Paul Sartre (p. 149); um poema do português Alexandre O’Neill sobre o medo (p. 143) e um fragmento de Baudelaire (p. 151); o início de "um conto memorável" (p. 153); um fragmento de Shakespeare (p. 116), "umas linhas do inglês George Orwell" (p. 168), mais precisamente de seu famoso romance 1984, do qual o medo é justamente um dos principais ingredientes.

O que é que se pode então concluir a propósito do sincretismo nessa obra de Antonio Torres? Por um lado, corroborar a assertiva de Néstor Garcia Canclini, já citada, para quem práticas discretas, que existem separadamente, se combinam para gerar outras estruturas e objetos. Mas também reconhecer no escritor a bagagem de técnicas e procedimentos da tradição literária do passado, aos quais dá um uso renovado. Porém, mais do que todos esses aspectos, salientar o desejo bem sucedido de focalizar cenas deixadas à sombra em nosso processo histórico, na medida que resgata episódios e personalidades até então vistos monoliticamente sem grandeza pelo discurso oficial. Para fugir à mirada canônica foi preciso, coerentemente, criar uma nova modalidade romanesca, esse romance híbrido, sincrético, mestiço, com formas articuladamente desarticuladas, pois esta é a única maneira de falar da fímbria e do não-dito. Aí repousa a grande originalidade de $O$ nobre seqüestrador.

Vemos assim de que modo opera a sintonia entre a literatura hispanoamericana e a que é praticada no Brasil. O hibridismo, tal como o realismo 
mágico e o fantástico, são tendências que ocorrem nas duas literaturas, embora no Brasil se verifiquem em muito menor proporção.

\section{Referências bibliográficas:}

BHABHA, Homi. O local da cultura. Belo Horizonte: Editora UFMG, 1998.

CORNEJO POLAR, Antonio. O condor voa. Literatura e cultura latino-americanas. Belo Horizonte: Editora da UFMG, 2000.

COUTINHO, Eduardo F. Teorias "transculturadas" o la migración de teorias en América Latina. In: D’ANGELO, Biaggio (ed). Espacios y discursos en literatura de América Latina. Lima, ICLA/ Fondo Editorial de la Universidad

Católica Sedes Sapientiae, 2003, p. 133-143.

DUGUAY-TROUIN. O corsário. Uma invasão francesa no Rio de Janeiro. Diário de bordo. Rio de Janeiro, Bom texto, 2002.

GARCÍA CANCLINI, Néstor. Culturas híbridas. 4ª ed. São Paulo: EDUSP, 2004.

OLMOS, Ana Cecília. As formas híbridas. In Bravo! ano 7, n 76, jan 2004, p. $92-$ 96.

PROENÇA FILHO, Domício. Oratório dos Inconfidentes (Faces do Verbo). Rio de Janeiro, Léo Christiano Editorial, 1989.

SAID, Edward. Traveling theory. In The world, the text and the critics. Cambridge: Massachussets, Harvard, 1983.

SANTIAGO, Silviano. O entre-lugar do discurso latino-americano. In: Uma literatura nos trópicos. São Paulo: Perspectiva, 1978. p.11-28.

SCHWARZ, Roberto. Ao vencedor as batatas. São Paulo: Duas Cidades, 1977.

TORRES, Antonio. Meu querido canibal. Rio de Janeiro: Record, 2000.

TORRES, Antonio. O nobre seqüestrador. Rio de Janeiro: Record, 2003.

VALDÉZ, Mario. Introdução. In: CORNEJO POLAR, Antonio. O condor voa. Literatura e cultura latino-americana. Belo Horizonte: Editora da UFMG, 2000 